Int. Agrophys., 2022, 36, 1-11

\title{
Analysis of relationship between head rice yield and breaking force of Japonica rice grains at different maturity stages**
}

\author{
Li Yinian (1)*, Chen Yulun, Ding Qishuo, He Ruiyin, and Ding Weimin \\ College of Engineering, Nanjing Agricultural University, Nanjing 210031, China \\ Received July 29, 2021; accepted January 4, 2022
}

\begin{abstract}
Maximum head rice yield is related to the optimal harvest time or moisture content during rice maturity. The physical properties of rice grains, such as the breaking forces, changed with the increasing degree of rice maturity. Harvest moisture content, breaking forces for the dorsal and ventral sides of the brown rice kernel in a three-point bending test and the milling quality properties of rice at different maturity stages were investigated. The relationships between head rice yield and harvest moisture content and also between head rice yield and the breaking forces for the dorsal side and ventral side were analysed. The breaking forces for the dorsal side and ventral side increased at 30/37 and at 44/51 days after heading and decreased at 58/65 days after heading, the increasing and decreasing extent of the breaking force for the ventral side was larger than that for the dorsal side. The breaking force for the ventral side was larger than that for the dorsal side during the maturity period. Head rice yield increased at 30/37 and at 44/51 days after heading, but head rice yield decreased at 58/65 days after heading. The breaking force for the ventral side increased by $9.52,10.13,8.59$, and $7.33 \mathrm{~N}$, head rice yield increased correspondingly $38.7,30.7,34.7$ and $15.3 \%$ during maturity for different varieties. The moisture content at optimal harvest time with the maximum head rice yield and maximum breaking force for ventral side or dorsal side was $25-30 \%$.

Keywords : rice maturity, moisture content, head rice yield, breaking force
\end{abstract}

*Corresponding author e-mail: liyinian@163.com

**This work was supported by the Fundamental Research Funds for the Central Universities under Grant KYYJ202106; State Key Research and Development Plan under Grant 2016YFD0300908 (2016-2020).

\section{INTRODUCTION}

Rice is the most important crop in China and half of the food demand of China is made up of rice products. The rice planting area is $29.694 \mathrm{mln}$ ha and the annual yield of rice was $200 \mathrm{mln} \mathrm{t}$ in 2019. Head rice yield (HRY) is among the most important indices for rice production, but there was also an optimal HRY during the rice maturity process. Rice caryopsis was filled with starch and protein matter, and the physical properties changed with the degree of maturity, however the degree of maturity and the physical properties of the rice grains at different maturity stages affected the HRY. The optimal rice harvest time with maximum HRY is only be determined using the rice moisture content (MC) at present, the rice MC is the result of the cultivation, environmental, and meteorological conditions, but it does not represent the real physical properties of rice grains, this is obviously unsatisfactory, instead HRY should be closely related to physical properties such as breaking force. On the other hand, structural differences exist between the dorsal side and ventral side, such as the size and shape of the starch granules (Xiong et al., 2005), the tissues on the ventral side were softer than those on the dorsal side and a higher number of airspaces and less starch were present

(C) 2022 Institute of Agrophysics, Polish Academy of Sciences 
on the ventral side than on the dorsal side (Masahiko et al., 2007). Because the structural differences between the dorsal side and ventral side caused differences in physical properties between the dorsal side and the ventral side, measurement of the breaking force for the dorsal side and ventral side was necessary to ascertain the effect of the degree of rice maturity on HRY from the point of view of the physical properties of rice.

The chemical and physical properties of rice grains changed with the increasing degree of their maturity (Bautista et al., 2005; Bautista et al., 2007; Shao et al., 2017). The size and weight of the rice grains increased with developing caryopsis (Wu et al., 2016). The moisture content (MC) of the rice grains decreased gradually at the maturity stage, and individual kernel MC distributions were multi-modal at the early harvest dates, the individual kernel MC distributions tended to be primarily single-modal as the average harvest $\mathrm{MC}$ reached about $16 \%$. This meant that the difference in $\mathrm{MC}$ among the rice kernels was large at the early harvest dates and the difference in MC gradually decreased with the increasing degree of maturity from the average harvest MC, from 26 to $16 \%$ (Siebenmorgen et al., 1992; Bautista et al., 2005). On the other hand, brown rice kernel dimensions decreased with harvest MC from 24 to $12 \%$. Among the kernel dimensions, the greatest degree of shrinkage occurred in thickness with decreasing harvest $\mathrm{MC}$, this was followed by length and then width (Bautista et al., 2007). Harvest MC affected the breaking force distributions of the rice grains and the closest correlations between head rice yield (HRY) and the percentage of strong kernels were found in the growing location/variety lots having HRYs of 45 to 65\% (Qin et al., 2005).

In terms of milling quality, grain yield, and the cost of drying rice grains, HRY was regarded as the most important aim by the farmer (Lanier et al., 2016). Many studies were conducted to investigate the factors that affected HRY during rice maturity. The MC of the rice was one of the most important factors. The general ranges of optimal harvest MC with peak HRY went from 19 to $22 \%$ for long-grains and from 22 to $24 \%$ for medium-grain cultivars (Siebenmorgen et al., 2007). The degree of HRY reduction increased with the increased percentages of both high and low MC kernels, the optimal harvest MC ranged from 18 to $22 \%$ for long-grain cultivars, from 19.0 to $20.4 \%$ for medium-grain cultivars, and from $17.7 \%$ to $19.0 \%$ for long-grain cultivars (Bautista et al., 2009). Lee et al. (2016) found that the maximum whole kernel ratio and grain yield for short-grain rice was in the $\mathrm{MC}$ range from 16.5 to $21 \%$, which was 3 to $6 \%$ lower than the MC at the general harvest time in South Korea. Lanier et al. (2016) found that the optimal harvest MC for maximizing HRY ranged from 17 to $22 \%$. Som et al. (2019a) found that HRY was more closely related to fissured grain than grain moisture content at harvest time. HRY of hand harvesting was $2-6 \%$ higher than that of combine harvesting at different ripening times
(Som et al., 2019b). The effect of rice harvest MC on the economic return to the farmer occurred at $\mathrm{MC}$ levels lower than $15 \%$ or higher than $22 \%$ (Lu et al., 1995). Lanier et al. (2016) found that the optimal harvest MC for maximizing the net value ranged from 16 to $20 \%$. The optimal harvest $\mathrm{MC}$ with the maximum HRY was found to be different by different research studies and the range for the optimal harvest $\mathrm{MC}$ was large.

The MC of the harvested rice was about $25 \%$ or more in the Jiangsu province of China, but the optimal MC values of the harvested rice for the above-mentioned research studies were $15-22 \%$. The optimal MC of the harvested rice for these research studies was not appropriate for the Jiangsu province of China, the HRY of the harvested rice with an MC value of $15-22 \%$ was not always optimal, but the maximum HRY was an important index for the farmer. The maximum HRY was not only related to the MC of the harvested rice, but also to the maturity degree of the rice or to other physical properties. Therefore, the objective of this research was to relate the maximum HRY to the rice harvest MC and also to the breaking forces for the ventral side and dorsal side of the rice grains at different maturity stages.

\section{MATERIALS AND METHODS}

Four Japonica rice cultivars, Ningjing-3, Wuyujing-23, Huaidao-9, and Yanjingdao were harvested from October to November 2011, 2012, 2013 and 2014 in the Jiangpu farm of Nanjing Agricultural University, Pukou District, Nanjing City, Jiangsu Province, China. Five or six samples were harvested at weekly intervals during the rice maturity season. The rice weight of each sample was $5 \mathrm{~kg}$ in the five harvested positions of the experimental field. The harvested paddy rice samples were immediately transported to the laboratory, cleaned, dried in shady conditions (room temperature and natural ventilation conditions) for three weeks in order to avoid drying damage to the rice grains and stored at a temperature of $4{ }^{\circ} \mathrm{C}$ for six months. At the same time, the $\mathrm{MC}$ value of the harvested paddy rice samples was measured immediately. The MC of the paddy rice samples was found to be uniform after storage. Then the peak breaking force and milling quality were tested after storage. Rice harvesting began 30 days after heading. The period for harvesting samples 1 and 2 took place at days 30/37 days after heading (DAH), the period for harvesting sample 3 and 4 took place at days $44 / 51 \mathrm{DAH}$, and the period for harvesting sample 5 and 6 took place at days 58/65 DAH. (Sample 4 for 2014 was not obtained due to continuously rainy weather.)

The MC of each harvested and stored rice sample at different maturity stages were measured by drying $10 \mathrm{~g}$ samples for $24 \mathrm{~h}$ in an oven pre-set at $130^{\circ} \mathrm{C}$ (Jindal et al., 1987). The MC testing of each sample was replicated three times. All MC values were expressed on a wet basis unless otherwise noted. 
The peak breaking force for three-point bending tests was obtained to study the mechanical properties of the rice kernels (ASAE Standards S459, 2001; Zhang et al., 2005). The breaking forces of brown rice kernel on both the dorsal side and ventral side were determined by using a three-point bending test device (the device was introduced in reference $\mathrm{Li}$ et al., 2014) and also by using a texture analyser (TMS-PRO, Food Technology Corporation, USA, Range: 0-500 N, precession speed: $30 \mathrm{~mm} \mathrm{~min}^{-1}$, accuracy: $0.01 \mathrm{~N}$ ). The relative operating method of the breaking force test was also shown in reference Li et al., 2014. The breaking force of the brown rice kernels for the three-point bending test was measured after the stored paddy rice was manually husked. The quantity of sound brown rice kernels for measuring breaking forces loaded on the dorsal side and the ventral side numbered 200 individual grains. The breaking force for the ventral side was measured by the loading head being loaded on the ventral side, the breaking force for the dorsal side was measured by the loading head being loaded on the dorsal side.

Four $100 \mathrm{~g}$ subsamples from each storage paddy rice sample were milled to determine the milling quality indices, brown rice yield, HRY, and broken rice yield. These milling quality indices were tested according to the National Standards of China GB/T5495-2008, GB/ T21719-2008 and GB/T5503-2009. Each subsample of rice was dehulled using a dehulling machine (THU35C, Satake Manufacturing (Suzhou) Co., Ltd), and each subsample of brown rice was milled for $20 \mathrm{~s}$ using a milling machine (CBS300AS, Satake Manufacturing Co., Ltd). In order to attain head rice, broken rice kernels were separated from the milling rice using a sieve.

A significance analysis was performed using SPSS 20, the significance between the two samples was tested using the Dunnett's method. Excel 2003 was used to calculate the average value and standard deviation.

\section{RESULTS AND DISCUSSION}

The MC of the harvested rice gradually decreased as the degree of maturity increased (Table 1). Firstly, the rice samples (sample 1) from every year were gathered after the rice had headed for about one month. The MC of the rice (sample 1) at $30 / 37$ DAH was $38-43 \%$ and the average moisture content of the rice was $41.5 \%$. After that, the sample was gathered at a weekly interval until the rice could be harvested normally. The MC of the rice (sample 6) at the last harvested time was about $22-26 \%$ and the average moisture content of the rice was $24.4 \%$. On the other hand, the $\mathrm{MC}$ of the rice at the same harvesting stage or maturity stage varied for different years, but the difference in the MC of the rice at the same harvesting stage or maturity stage for different years was in the range of $2-5 \%$.

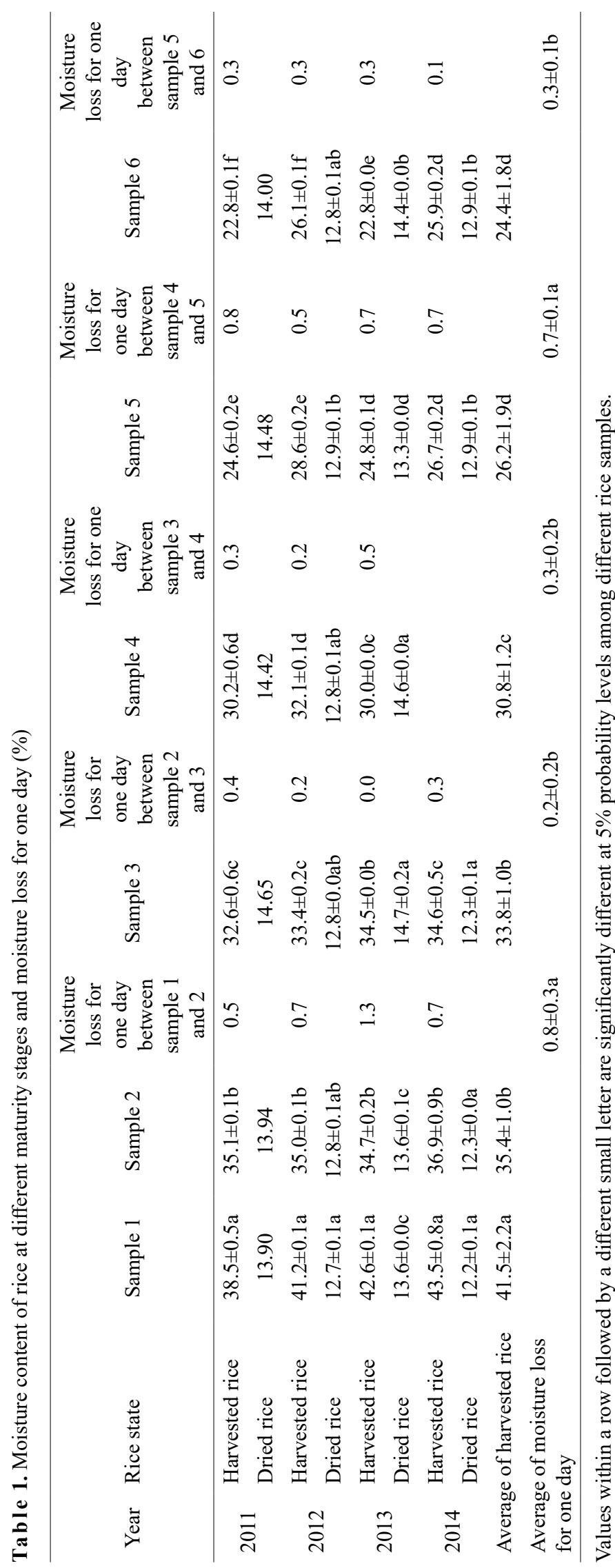


The MC of the harvested rice at different maturity stages did not decrease evenly, the dehydration rate at 30/37 DAH and at 58/65 DAH was greater than that at 44/51 DAH, the MC decreased quickly in the first week, the dehydration rate in the second and third week was low, the MC decreased quickly in the fourth week, but the MC decreased slowly in the last week. The dehydration rate at 58/65 DAH was slow.

In order to test the breaking force and milling properties, all of the rice samples at different maturity stages were dried in shade room conditions, and the MCs of the dried rice at different maturity stages were basically homogeneous (Table 1).

The moisture loss for one day during rice maturity is shown in Table 1. The moisture loss for one day varied at different maturity stages. The moisture loss for one day at $30 / 37$ (DAH) was high, and then it became lower over the following two weeks. The moisture loss for one day was large in the fourth week, whereas the moisture loss for one day was still low in the last week.

The breaking forces for the ventral side and dorsal side increased with the degree of rice maturity at 30/37 DAH and at 44/51 DAH (Table 2), but those breaking forces for the ventral side and the dorsal side decreased with the degree of rice maturity at 58/65 DAH. The breaking force could account for the structural strength of the rice grain. Therefore, the structural strength of the rice also increased with the degree of maturity at 30/37 DAH and at 44/51 $\mathrm{DAH}$, but the structural strength of the rice decreased with the degree of maturity at 58/65 DAH. The breaking force for the ventral side was always larger than that for the dorsal side at the whole maturity stage (Li et al., 2014). This means that the structural strength of the ventral side was lower than that of the dorsal side at the whole maturity stage.

The breaking forces for the ventral and dorsal sides increased with the degree of rice maturity, but the increasing extent of the breaking force for the ventral side and dorsal side was different, the extent of the increase for the ventral side was larger than that for the dorsal side (Table 2), this means that the grain filling rate on the dorsal side was higher than that on the ventral side at the whole maturity stage. The increasing extent of the breaking force for the ventral side was represented by the difference in the breaking force of the rice grains between the maximum and the original stage for the ventral side, and the increasing extent of the breaking force for the ventral side were 9.52, 10.13, 8.59 and $7.33 \mathrm{~N}$ respectively for the different varieties harvested in 2011, 2012, 2013 and 2014.

Table 2. Breaking force for the ventral side and the dorsal side of brown rice at different maturity stages and the difference in the breaking force for the ventral side and the dorsal side between the maximum and original stage and also the difference in the breaking force for the ventral side and the dorsal side between the maximum and final stage $(\mathrm{N})$

\begin{tabular}{|c|c|c|c|c|c|}
\hline \multirow{2}{*}{ Sample No. } & \multirow{2}{*}{ Loading side } & \multicolumn{4}{|c|}{ Breaking force } \\
\hline & & 2011 & 2012 & 2013 & 2014 \\
\hline \multirow{2}{*}{1} & Ventral side & $25.89 \pm 9.61 \mathrm{a}$ & $40.09 \pm 12.42 \mathrm{a}$ & $27.28 \pm 9.52 \mathrm{a}$ & $34.68 \pm 11.67 \mathrm{a}$ \\
\hline & Dorsal side & $23.76 \pm 7.03 \mathrm{a}$ & $37.00 \pm 9.44 b$ & $25.84 \pm 10.44 a$ & $29.99 \pm 8.68 \mathrm{a}$ \\
\hline \multirow{2}{*}{2} & Ventral side & $33.33 \pm 6.40 \mathrm{c}$ & $47.22 \pm 11.36 b c$ & $29.82 \pm 8.60 \mathrm{~b}$ & $37.74 \pm 14.47 \mathrm{~b}$ \\
\hline & Dorsal side & $26.54 \pm 5.33 b$ & $39.96 \pm 10.31 \mathrm{c}$ & $28.45 \pm 7.67 b$ & $31.08 \pm 9.14 \mathrm{c}$ \\
\hline \multirow{2}{*}{3} & Ventral side & $31.38 \pm 5.88 \mathrm{~b}$ & $50.23 \pm 11.29 \mathrm{~d}$ & $29.93 \pm 7.10 b$ & $40.81 \pm 11.29 \mathrm{c}$ \\
\hline & Dorsal side & $28.58 \pm 4.71 \mathrm{c}$ & $40.28 \pm 9.89 c$ & $28.73 \pm 8.30 \mathrm{~b}$ & $28.42 \pm 9.82 b$ \\
\hline \multirow{2}{*}{4} & Ventral side & $35.41 \pm 5.05 \mathrm{~d}$ & $45.96 \pm 12.37 b$ & $31.53 \pm 6.57 \mathrm{c}$ & \\
\hline & Dorsal side & $27.26 \pm 5.07 \mathrm{bc}$ & $39.72 \pm 9.98 \mathrm{c}$ & $31.83 \pm 8.14 \mathrm{c}$ & \\
\hline \multirow{2}{*}{5} & Ventral side & $34.11 \pm 5.30 \mathrm{~cd}$ & $49.04 \pm 10.12 \mathrm{~cd}$ & $35.87 \pm 8.17 \mathrm{~d}$ & $42.01 \pm 12.31 \mathrm{c}$ \\
\hline & Dorsal side & $28.46 \pm 5.00 \mathrm{c}$ & $41.62 \pm 10.98 \mathrm{c}$ & $34.31 \pm 6.83 \mathrm{~d}$ & $29.49 \pm 9.10 b c$ \\
\hline \multirow{2}{*}{6} & Ventral side & $33.52 \pm 4.81 \mathrm{c}$ & $40.97 \pm 8.46 \mathrm{a}$ & $35.48 \pm 5.83 \mathrm{~d}$ & $40.38 \pm 11.24 \mathrm{c}$ \\
\hline & Dorsal side & $30.61 \pm 5.56 \mathrm{~d}$ & $35.01 \pm 8.96 \mathrm{a}$ & $34.18 \pm 6.77 \mathrm{~d}$ & $31.92 \pm 9.33 \mathrm{~cd}$ \\
\hline \multicolumn{6}{|c|}{ Difference between maximum and original stage for } \\
\hline \multicolumn{2}{|c|}{ dorsal side } & 6.85 & 4.62 & 8.47 & 1.93 \\
\hline \multicolumn{2}{|c|}{ ventral side } & 9.52 & 10.13 & 8.59 & 7.33 \\
\hline \multicolumn{6}{|c|}{ Difference between maximum and last stage for } \\
\hline \multicolumn{2}{|c|}{ dorsal side } & 0.00 & 6.62 & 0.13 & 0.00 \\
\hline \multicolumn{2}{|c|}{ ventral side } & 1.89 & 9.26 & 0.39 & 1.63 \\
\hline
\end{tabular}

Values within a column followed by a different small letter are significantly different at $5 \%$ probability levels among the ventral sides. 
The difference in the breaking force of the rice grains between the maximum and the original stage for the ventral side was larger than that for the dorsal side (Table 2). It meant that the structural strength of the dorsal side increased more quickly than that of the ventral side at $30 / 37 \mathrm{DAH}$, and that the grain filling rate was higher on the dorsal side than on the ventral side, therefore the structural strength of the dorsal side was higher than that of the ventral side. The decreasing extent of the breaking force of the rice grains between the maximum and last stage for the dorsal side and the ventral side was lower than the increasing extent of the breaking force of the rice grains between the maximum and the original stage for the dorsal side and the ventral side apart from 2012 for the dorsal side. On the other hand, a difference in the breaking force of the rice grains between the maximum and the last stage for the ventral side was larger than that of the dorsal side; this means that the structural strength of the dorsal side decreased more quickly than that of the ventral side at 58/65 DAH. The decreasing extent of the structural strength for the dorsal and ventral side at 58/65 DAH was lower than the increasing extent of the structural strength for the dorsal and ventral side at 30/37 DAH apart from the year 2012 . The decreasing extent of the breaking force for the ventral side was represented by the difference in the breaking force of the rice grains between the maximum and the last stage for the ventral side, and the increasing extent of the breaking force for the ventral side were 1.89, 9.26, 0.39 and $1.63 \mathrm{~N}$, respectively for the different varieties in 2011, 2012, 2013 and 2014.

Although, this also meant that there was more inner damage on the dorsal side than on the ventral side at 58/65 $\mathrm{DAH}$, but the structural strength of the dorsal side at the whole maturity stage was larger than that of the ventral side, so that the initial fissure in the rice grain still appeared at the ventral side when rice grains were under the adsorption and desorption conditions in the field. This corresponded to research that the fissure was produced and first appeared at the ventral side of the rice grain (Zhang et al., 2003).

The brown rice yield, HRY and broken rice yield of the harvested rice during the whole maturity phase are shown in Table 3. The brown rice yield increased with the degree of rice maturity. The increasing extent was large at 30/37 DAH, but the increasing extent at $44 / 51$ and at 58/65 DAH was small or remained steady. HRY increased with the degree of rice maturity at 30/37 and at 44/51 DAH, HRY increased by $38.7,30.7,34.7$ and $15.3 \%$, respectively for the different varieties in 2011, 2012, 2013 and 2014, and then HRY decreased at 58/65 DAH by 12.9 and $11.0 \%$, respectively in 2011 and 2013. The broken rice yield decreased with the degree of rice maturity, but the broken rice yield increased by $14.8,3.0$ and $8.9 \%$, respectively at $58 / 65 \mathrm{DAH}$ in 2011 , 2012 and 2013. The variation trend in the broken rice yield was the opposite to that of the variation trend of the HRY. The HRY increased with rice maturity, but over-maturity or
Table 3. Milling quality indexes of rice at different maturity stages $(\%)$

\begin{tabular}{|c|c|c|c|}
\hline Year & $\begin{array}{l}\text { Brown } \\
\text { rice yield }\end{array}$ & $\begin{array}{l}\text { Head } \\
\text { rice yield }\end{array}$ & $\begin{array}{c}\text { Broken rice } \\
\text { yield }\end{array}$ \\
\hline \multicolumn{4}{|c|}{ Sample 1} \\
\hline 2011 & $70.5 \pm 1.5 \mathrm{a}$ & $17.2 \pm 2.5 \mathrm{a}$ & $32.8 \pm 2.7 \mathrm{a}$ \\
\hline 2012 & $77.2 \pm 0.7 \mathrm{a}$ & $32.0 \pm 0.8 \mathrm{a}$ & $17.6 \pm 0.6 \mathrm{a}$ \\
\hline 2013 & $80.1 \pm 0.3 \mathrm{a}$ & $34.9 \pm 0.7 \mathrm{a}$ & $15.2 \pm 0.7 \mathrm{a}$ \\
\hline 2014 & $79.7 \pm 0.2 \mathrm{a}$ & $55.1 \pm 1.1 \mathrm{a}$ & $9.7 \pm 0.3 \mathrm{a}$ \\
\hline \multicolumn{4}{|c|}{ Sample 2} \\
\hline 2011 & $79.4 \pm 0.5 b$ & $47.7 \pm 6.6 c$ & $16.8 \pm 8.5 \mathrm{~d}$ \\
\hline 2012 & $79.8 \pm 0.8 b$ & $48.5 \pm 0.6 b$ & $11.9 \pm 0.0 \mathrm{~b}$ \\
\hline 2013 & $80.6 \pm 0.3 b$ & $50.3 \pm 0.8 b$ & $9.6 \pm 0.6 \mathrm{c}$ \\
\hline 2014 & $82.8 \pm 0.2 b$ & $63.6 \pm 0.9 b$ & $5.3 \pm 0.0 \mathrm{~b}$ \\
\hline \multicolumn{4}{|c|}{ Sample 3} \\
\hline 2011 & $80.4 \pm 0.9 c$ & $53.4 \pm 0.2 \mathrm{~d}$ & $12.8 \pm 0.7 \mathrm{e}$ \\
\hline 2012 & $80.4 \pm 0.6 b$ & $55.8 \pm 1.6 \mathrm{c}$ & $9.4 \pm 0.2 \mathrm{c}$ \\
\hline 2013 & $81.8 \pm 0.3 c$ & $49.6 \pm 1.7 b$ & $11.7 \pm 0.0 \mathrm{~b}$ \\
\hline 2014 & $83.1 \pm 0.1 \mathrm{c}$ & $65.4 \pm 1.2 b$ & $3.9 \pm 0.1 \mathrm{c}$ \\
\hline \multicolumn{4}{|c|}{ Sample 4} \\
\hline 2011 & $80.3 \pm 0.7 \mathrm{c}$ & $55.9 \pm 0.3 \mathrm{~d}$ & $12.1 \pm 1.6 \mathrm{e}$ \\
\hline 2012 & $81.7 \pm 0.1 \mathrm{c}$ & $57.3 \pm 1.0 \mathrm{~cd}$ & $9.7 \pm 0.8 \mathrm{c}$ \\
\hline 2013 & $83.0 \pm 0.1 \mathrm{~d}$ & $65.9 \pm 2.3 \mathrm{~d}$ & $6.6 \pm 1.1 \mathrm{~d}$ \\
\hline 2014 & - & - & - \\
\hline \multicolumn{4}{|c|}{ Sample 5} \\
\hline 2011 & $80.3 \pm 0.0 \mathrm{c}$ & $49.1 \pm 5.2 \mathrm{~cd}$ & $19.8 \pm 5.8 \mathrm{c}$ \\
\hline 2012 & $81.8 \pm 0.0 \mathrm{c}$ & $62.7 \pm 1.3 \mathrm{~d}$ & $6.2 \pm 0.5 \mathrm{~d}$ \\
\hline 2013 & $82.9 \pm 0.2 \mathrm{~d}$ & $69.6 \pm 2.0 \mathrm{e}$ & $4.7 \pm 0.9 \mathrm{e}$ \\
\hline 2014 & $84.0 \pm 0.1 \mathrm{~d}$ & $70.4 \pm 0.9 \mathrm{c}$ & $3.9 \pm 0.3 c$ \\
\hline \multicolumn{4}{|c|}{ Sample 6} \\
\hline 2011 & $80.2 \pm 0.4 c$ & $43.0 \pm 1.1 \mathrm{~b}$ & $26.9 \pm 0.3 b$ \\
\hline 2012 & $83.0 \pm 0.1 \mathrm{c}$ & $59.1 \pm 1.1 \mathrm{~cd}$ & $9.2 \pm 0.8 \mathrm{c}$ \\
\hline 2013 & $82.9 \pm 0.1 \mathrm{~d}$ & $58.6 \pm 0.6 \mathrm{c}$ & $13.6 \pm 0.1 \mathrm{a}$ \\
\hline 2014 & $84.7 \pm 0.0 \mathrm{e}$ & $70.3 \pm 0.5 \mathrm{c}$ & $4.0 \pm 0.3 \mathrm{c}$ \\
\hline
\end{tabular}

Values within a column followed by a different small letter are significantly different at $5 \%$ probability levels among different rice samples.

late harvesting caused the HRY to decrease and the broken rice yield to increase. The optimal harvest time of the rice was very important for the HRY. There was a maximum HRY during the rice maturity process. In order to attain the maximum HRY value, the rice should be harvested at periods of maximum HRY. The minimum broken rice yield and the maximum brown rice yield was always at or adjacent to the maximum HRY point. 
The relationship between the MC of the harvested rice and the breaking forces for different years are shown in Fig. 1. The breaking forces for the ventral side and the dorsal side increased with the MC of the harvested rice and decreased at 30/37 or at 44/51 DAH. The breaking force for the ventral side decreased with the MC of the harvested rice and decreased to its lowest level at 58/65 DAH. In summary, the maximum breaking force for the ventral side occurred at $44 / 51$ or at $58 / 65$ DAH with the higher MC of the harvested rice. Also, the maximum breaking force for the dorsal side occurred at 58/65 DAH or at the final maturity stage with the lower MC of the harvested rice. The correlation coefficients between the MC of the harvested rice and the breaking force for different years were very different, there was no significant correlation between the breaking force and the rice maturity stage according to the correlation coefficients except for 2013.

The relationship between the MC of the harvested rice and the HRY value is shown in Fig. 2. HRY is among the most important indexes for the rice farmer, the HRY increased with the decreasing $\mathrm{MC}$ of the harvested rice, but in contrast, the HRY value was reduced at the last harvest stage, the optimal harvest time with the maximum HRY could not be determined at the last harvest stage with the minimum MC. The MC of rice with the maximum HRY
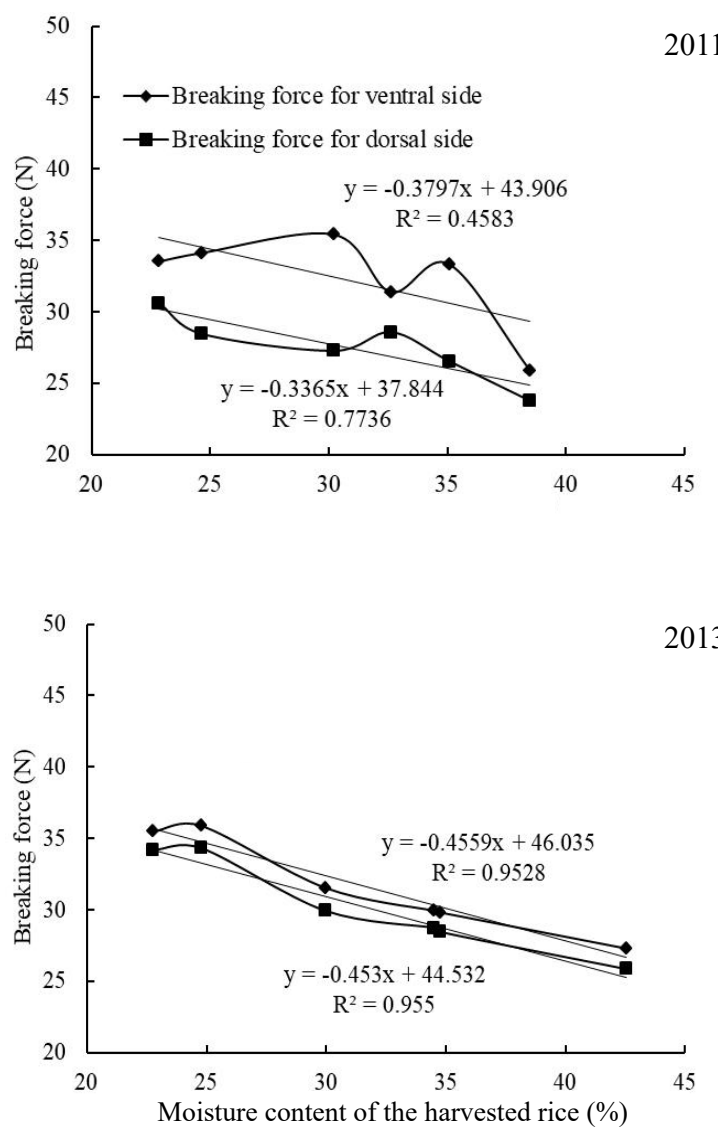

occurred at 25-30\%. This optimal harvest MC for Japonica rice in the Jiangsu Province of China was higher than it was for other studies, such as studies by Siebenmorgen et al. (1992, 2007), Lee et al. (2016), Bautista et al. (2009), Lanier et al. (2016), which were also limited to a particular place with a specific climate. The correlation coefficients between the MC of the harvested rice and the HRY for different years were different, the correlation coefficients for 2012, 2013 and 2014 were relatively large, and this meant that the HRY was related to the rice maturity stage.

The correlation coefficients between HRY and the milling quality and mechanical properties of brown rice during maturity are shown in Table 4 . The correlation coefficients between the HRY and the milling quality and breaking force for the ventral side were $0.890,0.548,0.836$ and 0.936 , respectively in 2011, 2012, 2013 and 2014. The correlation coefficients between HRY and the milling quality and breaking force for the dorsal side were $0.649,0.331$, 0.820 and 0.158 , respectively in 2011, 2012, 2013 and 2014. The correlation coefficients between HRY and the milling quality and sum of the breaking force for the ventral and dorsal side were $0.861,0.479,0.828$ and 0.993 , respectively in 2011, 2012, 2013 and 2014. The correlation coefficients between HRY and the milling quality and difference in breaking force for the ventral and dorsal side
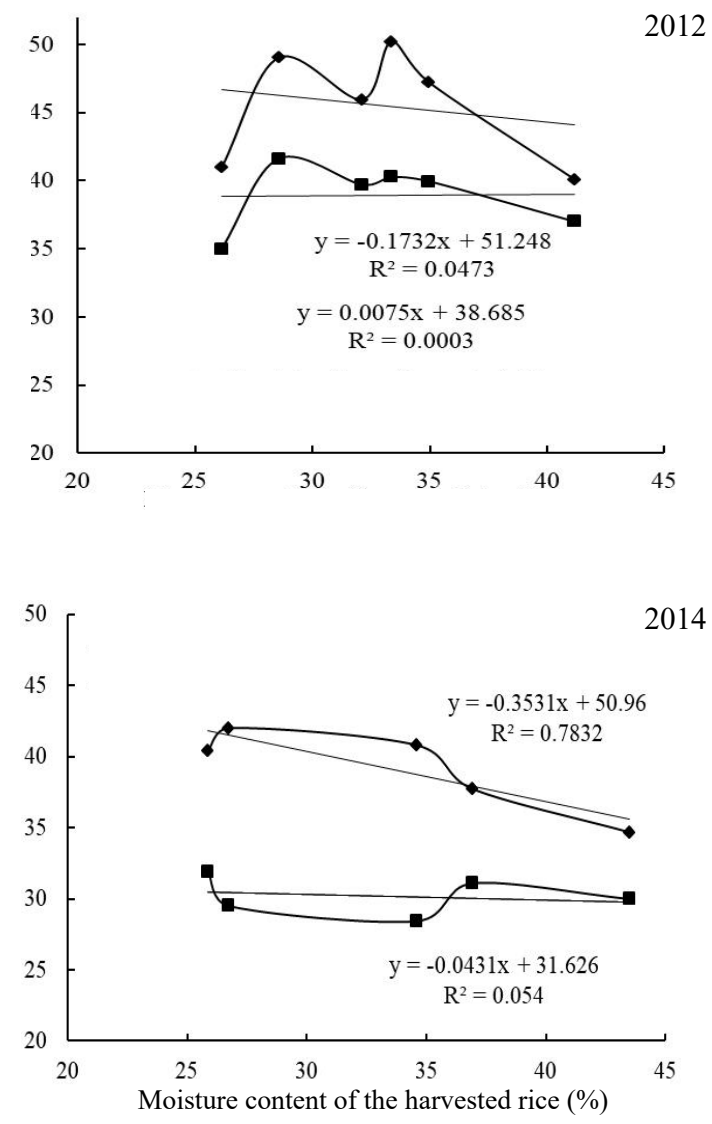

Fig. 1. Relationship between the moisture content of the harvested rice and the breaking forces for different years. 

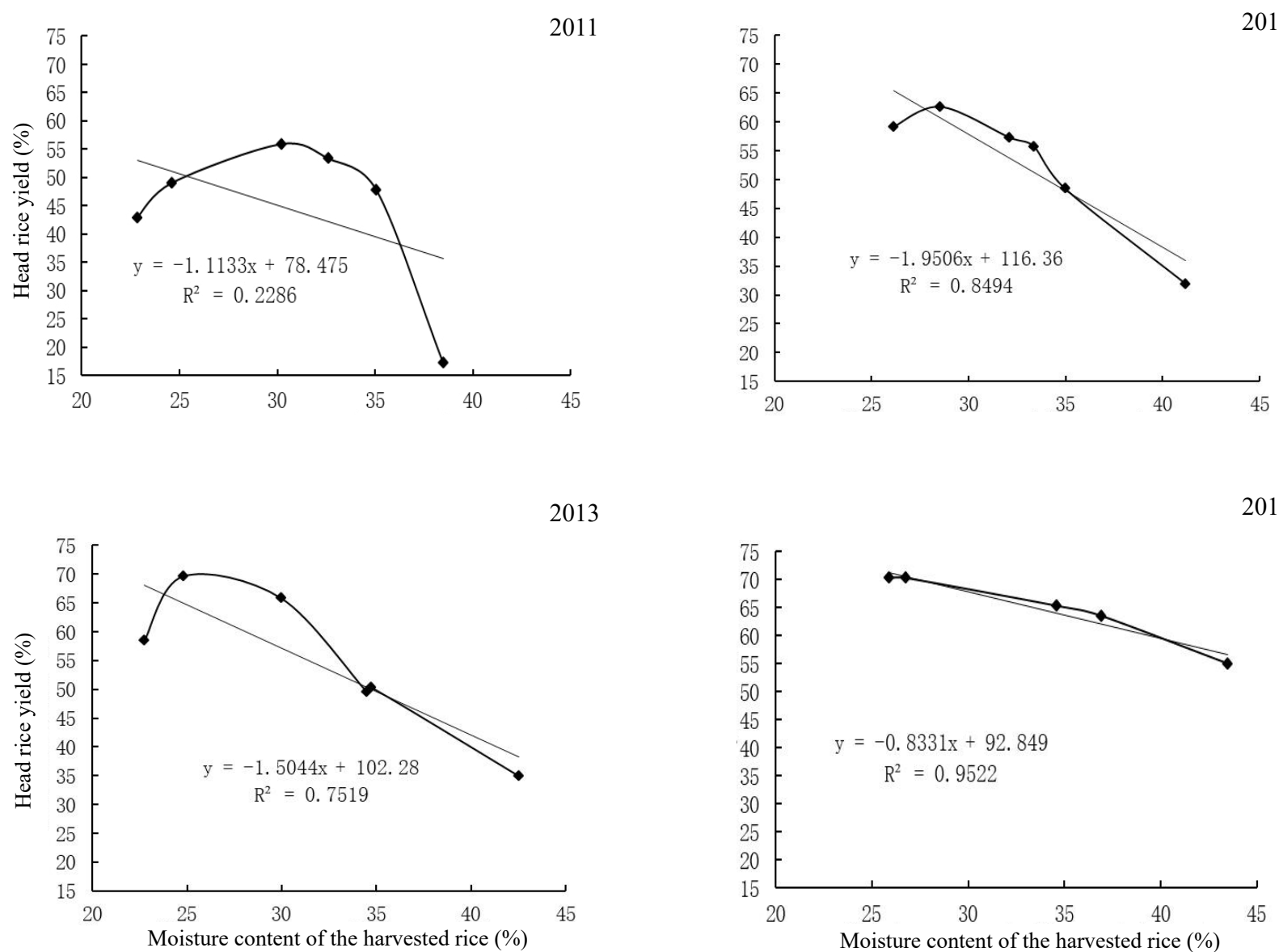

Fig. 2. Relationship between the moisture content of the harvested rice and the head rice yield for different years.

Table 4. Correlation coefficient between head rice yield and mechanical properties of the rice at different maturity stages

\begin{tabular}{|c|c|c|c|c|}
\hline \multirow{3}{*}{ Year } & \multicolumn{4}{|c|}{ Correlation coefficient between head rice yield and } \\
\hline & \multicolumn{2}{|c|}{ Three-point bending breaking force for } & \multirow{2}{*}{$\begin{array}{l}\text { Sum of the three-point } \\
\text { bending breaking force for } \\
\text { the ventral and dorsal side }\end{array}$} & \multirow{2}{*}{$\begin{array}{l}\text { Difference in the three- } \\
\text { point bending breaking } \\
\text { force between the ventra } \\
\text { side and the dorsal side }\end{array}$} \\
\hline & Ventral side & Dorsal side & & \\
\hline 2011 & $0.890 * *$ & 0.649 & $0.861 *$ & 0.613 \\
\hline 2012 & 0.548 & 0.331 & 0.479 & 0.663 \\
\hline 2013 & $0.836^{*}$ & $0.820 *$ & $0.828 *$ & 0.474 \\
\hline 2014 & $0.936^{* *}$ & 0.158 & $0.993 * *$ & 0.728 \\
\hline
\end{tabular}

Significant at: $* \mathrm{p}<0.05, * * \mathrm{p}<0.01$.

were $0.613,0.663,0.474$ and 0.728 , respectively in 2011 , 2012, 2013 and 2014. The correlation coefficients between HRY and the breaking force for the ventral side, dorsal side, the sum of these values for the ventral and dorsal side and the difference in these values between the ventral side and dorsal side were different. The correlation coefficients between HRY and the breaking force for the ventral side were maximized, and the correlation between the HRY and the breaking force for the ventral side was also significant apart from 2012. The correlation between the HRY and the sum of the breaking force for the ventral and dorsal side was also significant apart from 2012. The correlation coefficients between HRY and the breaking force for the dorsal side and difference of breaking force for the ventral side and dorsal side were minimized. This means that the breaking force for the ventral side reflects the structural strength 

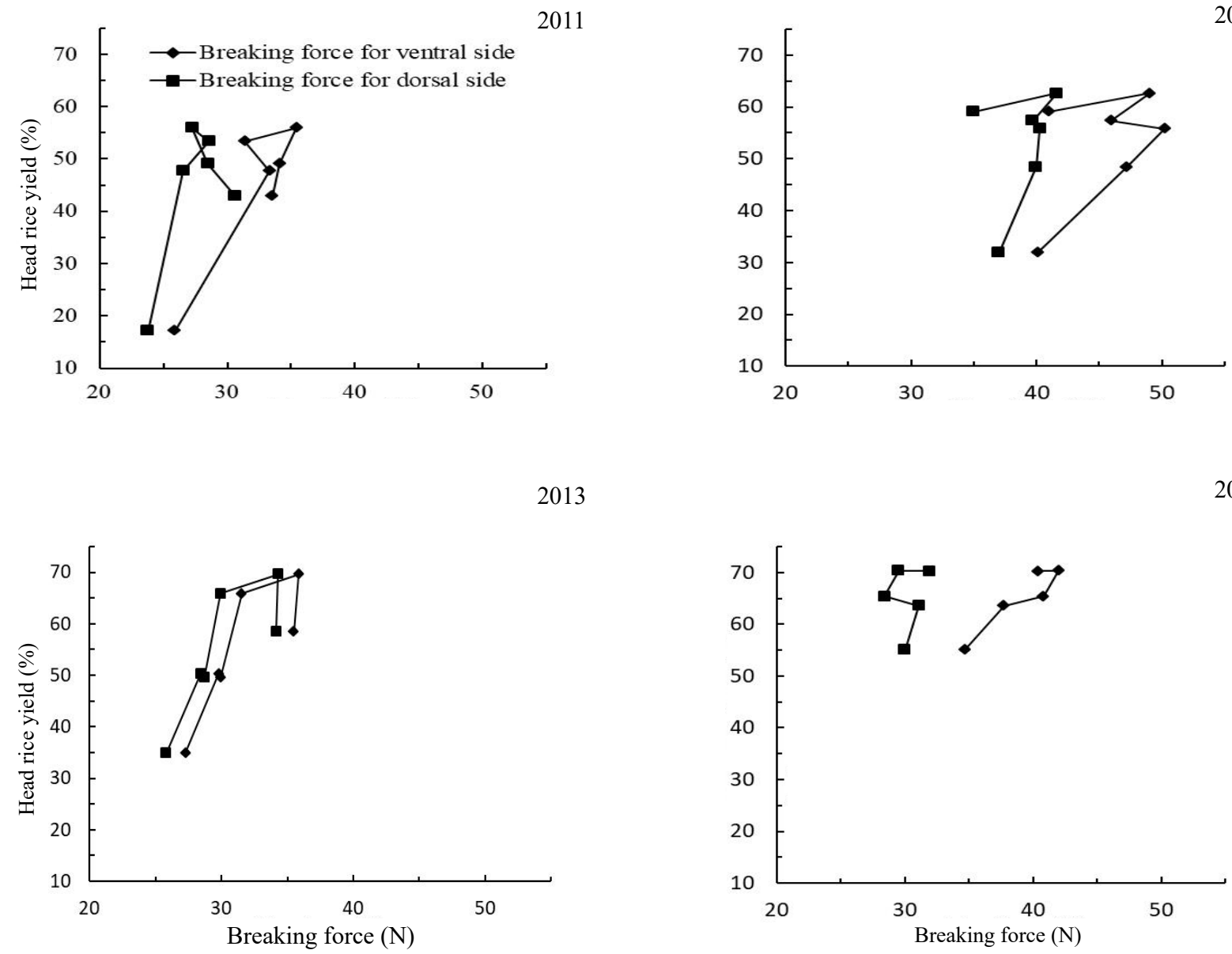

Fig. 4. Relationship between the breaking force for the ventral side and the head rice yield and between the breaking force for the dorsal side and the head rice yield.

of the rice and the HRY. The breaking force for the ventral side of the rice grains was among the most important mechanical properties that were related to HRY.

The relationship between the breaking force for the ventral side and HRY are shown in Fig. 3. The breaking force for the ventral side increased with the degree of maturity of the rice at 30/37 and 44/51 DAH, HRY also increased with the degree of maturity of the rice. The breaking force for the ventral side increased by $9.52,10.13,8.59$ and $7.33 \mathrm{~N}$, and HRY increased by $38.7,30.7,34.7$ and $15.3 \%$ for different varieties in 2011, 2012, 2013 and 2014 respectively. But the breaking force for the ventral side decreased with the degree of rice maturity at $44 / 51$ and $58 / 65 \mathrm{DAH}$, the HRY also decreased with the degree of rice maturity. This means that HRY increased or decreased, respectively with increases or decreases in the breaking force. When the breaking force for the ventral side was maximized, the HRY was also maximized, apart from 2012. The maximum HRY did not occur at the maximal breaking force point in 2012, however, the breaking force reached its second high- est value. The sum of the increasing extent of the breaking force for the ventral side and dorsal side were 16.37, 14.75, 17.06 and $14.14 \mathrm{~N}$, respectively for the different varieties and were related to the increasing extent of the head rice yield at $38.7,30.7,34.7$ and $15.3 \%$, respectively for the different varieties in 2011, 2012, 2013 and 2014 and the coefficient of determination $\mathrm{R}^{2}$ was 0.67 .

The relationship between the breaking force for the dorsal side and HRY are shown in Fig. 3. The relationship between the breaking force for the dorsal side and HRY was similar to that for the ventral side. When the breaking force for the dorsal side was maximized, the HRY was also maximized, apart from 2011. Although the relative coefficients between the breaking force for the dorsal side and HRY were low, the maximum HRY of the harvested rice during maturity always corresponded to the maximum or at least to a large breaking force for the dorsal side.

The main material, protein and starch, filled the grain at the developing rice caryopsis stage. The dimensions of the rice grain increased at this stage (Wu et al., 2016). The 
filling matter rate on the dorsal and the ventral side were different (Ellis et al., 1987). A greater abundance of protein was distributed in the dorsal half of the endosperm as opposed to the ventral half, this was related to the nucellar epidermis which restricts endosperm protein deposition initially at the ventral margin, and subsequently spreads laterally and dorsally (Ellis et al., 1987). The number of layers of aleurone cells on the dorsal and ventral sides was also different (Wu et al., 2016), amyloplasts were sparser in the sub-aleurone cells of the dorsal and lateral parts of the caryopsis and amyloplasts were sparsest in the subaleurone cells of the ventral part of the caryopsis (Zheng et al., 2017). Therefore, the structural strength for the dorsal side and the ventral side was different at the subsequent maturity stage, the mechanical properties of the rice grains for the dorsal side and the ventral side were different. The rice $\mathrm{MC}$ gradually decreased at the final maturity stage, the maximum breaking force occurred at the whole maturity process, the breaking force at the last harvest time always decreased. The maximum HRY occurred at the whole maturity process, the HRY at the last harvest time also decreased. The variability trends of the breaking forces for the dorsal side and the ventral side were similar to those in HRY. This means that the HRY was related to the breaking force of the rice grain. The increasing extent of the breaking force with rice maturity for the dorsal side was always larger than that for the ventral side, this means that more matter was filled on the dorsal side as compared to the ventral side, so the structural strength of the rice for the dorsal side was always greater than that for the ventral side. When the MC of the rice grains was lower than a certain critical value, the rice grains absorbed moisture from the wet air environment or rain water, because it has rained for a long time at rice harvest time in the Jiangsu province of China especially in recent years. The decreasing extent of the breaking force for the dorsal side was always larger than that for the ventral side at the late maturity stage. This means that the grain absorbing moisture caused more damage on the dorsal side than on the ventral side at the late maturity stage (Thomson et al., 2006). The structural strength on the dorsal side was still greater than that on the ventral side during the maturity of the crop, the initial fissure still appeared on the ventral side because of rice adsorbing moisture from the wet environment (Li et al., 2010; Jia et al., 2002; Zhang et al., 2003), and those fissures on the ventral side also caused a further reduction in the structural strength of the rice grain (Zhang et al., 2005; Siebenmorgen et al., 2005). In summary, the HRY decreased with a reduction in the structural strength of the rice grains. The optimal harvest MC (time) with the maximum HRY and the maximum structural strength of rice grains should be selected during rice maturity.

MC affected the physical properties of the rice grain during maturity; the rice grain required water to become full at 30/37 DAH, then MC decreased gradually. When the $\mathrm{MC}$ of the rice grains decreased below a critical value, the rice grains adsorbed moisture from the wet air and rain, the fissures easily appeared on the ventral side of the rice grains. Therefore, the optimal harvest time was decided by the MC of the rice. The optimal harvest MC of the rice with a maximum HRY was $25-30 \%$ in the Jiangsu province of China, this optimal harvest MC was higher than the $17-22 \%$ optimal harvest MC that was reported in the literature (Siebenmorgen et al., 2007; Bautista et al., 2009; Lanier et al., 2016; Lee et al., 2016). The optimal harvest MC with maximum HRY for the different regions was not the same, this phenomenon may be related to the wet environment and local meteorological conditions (Thomson et al., 2006). Therefore, the optimal harvest time should not only be determined by the harvest MC but should also be determined by the structural strength or breaking force of the rice grains.

On the other hand, if the drying cost of the rice that was dried from a high MC with the maximum HRY to a low MC at the final harvesting stage was lower than the loss due to the broken rice, which was from the low broken rice yield stage with the maximum HRY to the high broken rice yield at the last harvesting stage, the optimal harvest time for the rice would be at the high MC level with the maximum HRY.

The main problem of rice production was that high losses occurred due to broken rice during the late maturity phase. Rice milling breakage was closely related to the mechanical strength of the rice grains, the mechanical strength of the rice grains was related to the occurrence of rice fissures (Zhang et al, 2005). These fissures are caused by an uneven gradient of moisture absorption by rice in the field. Fissure finally caused rice breakage in the milling process. A decrease in the broken rice yield means a decrease in the loss overall. Preventing the fissures of rice grain from appearing and the strength of rice grains from decreasing were especially important problems during the whole maturity period. The HRY was related to the harvest MC during the rice maturity period, but the HRY was more closely related to the strength of the rice grain than to the harvest MC.

There was a limit to the determination of the optimal harvest time with the maximum HRY according to the rice MC during the rice maturity process. Determining the optimal harvesting time of the rice to achieve the maximum HRY using rice MC measurements is not compatible with any particular location or any harvesting scenario at present. The physical properties, and breaking force of the rice grains may be applicable in any location or any harvesting scenario for the determination of the optimal harvesting time of the rice with the maximum HRY. 


\section{CONCLUSIONS}

1. The grain filling rate on the dorsal side was greater than that on the ventral side at the rice kernel development stage, filled matter on the dorsal side was greater than that on the ventral side, therefore, the structural strength of the rice for the dorsal side was always larger than that of the ventral side, and the breaking force for the ventral side was larger than that of the dorsal side during the whole of the maturity period.

2. MC decreased with the degree of rice maturity, this process continued until the harvest, the breaking force in the three-point bending test increased with the degree of rice maturity increasing, but the breaking force decreased at the final maturity stage, the brown rice yield increased with the degree of rice maturity increasing, but the brown rice yield remained steady at 58/65 DAH, the HRY increased with the degree of rice maturity increasing, but HRY decreased at 58/65 DAH, the variation in the broken rice yield followed the opposite trend as HRY. It was concluded that the minimum $\mathrm{MC}$ at the last maturity stage could not be used to determine the maximum HRY and the breaking force. The breaking force for the ventral side increased by 9.52, 10.13, 8.59 and $7.33 \mathrm{~N}, \mathrm{HRY}$ increased correspondingly by 38.7 , $30.7,34.7$ and $15.3 \%$, respectively during maturity for different varieties in 2011, 2012, 2013 and 2014. The MC values of the rice with maximum HRY and breaking force were always larger than the $\mathrm{MC}$ values at the final maturity stage, therefore ascertaining the optimum harvest time for the rice was necessary. HRY was not only related to the rice maturity stage or MC but it was also related to the breaking force of the rice grains. The optimum harvest $\mathrm{MC}$ of the rice with the maximum HRY and maximum breaking force for the ventral side or the dorsal side was $25-30 \%$. The maximum breaking force may be regarded as another method for determining the optimal rice harvest time.

Conflict of interest. All authors declare no conflict of interest.

\section{REFERENCES}

ASAE, 2001. ASAE Standards S459: Shear and three point bending test of animal bone. Am. Soc. Agric. Eng., St. Joseph, MI, USA.

Bautista R.C., and Siebenmorgen T.J., 2005. Individual kernel rice moisture content variability trends. Appl. Eng. Agric., 21(4), 637-643. https://doi.org/10.13031/2013.18552

Bautista R.C., Siebenmorgen T.J., and Counce P.A., 2007. Rice kernel dimensional variability trends. Appl. Eng. Agric.,23(2),207-217.https://doi.org/10.13031/2013.22600

Bautista R.C., Siebenmorgen T.J., and Mauromoustakos A., 2009. The role of rice individual kernel moisture content distributions at harvest on milling quality. Trans. ASABE, 52(5), 1611-1620. https://doi.org/10.13031/2013.29112

Ellis J.R., Gates P.J., and Boulter D., 1987. Storage-protein deposition in the developing rice caryopsis in elation to the transport tissues. Annals Botany, 60(6), 663-670. https://doi.org/10.1093/oxfordjournals.aob.a087497
Jia C.C., Yang W., Siebenmorgen T.J., Bautista R.C., and Cnossen A.G., 2002. A study of rice fissuring by finiteelement simulation of internal stresses combined with high-speed microscopy imaging of fissure appearance. Trans. ASAE, 45(3), 741-749. https://doi.org/10.13031/2013.8852

Jindal V.K. and Siebenmorgen T.J., 1987. Effects of oven drying temperature and drying time on rough rice moisture content determination. Trans. ASAE, 30(4), 1 185-1 192. https://doi.org/10.13031/2013.30542

Lanier N., Bruce D., Jesse T., Andrew B., and Krishna J., 2016. Optimal harvest moisture content for maximizing midsouth rice milling yields and returns. Agronomy J., 108(2), 701-712. https://doi.org/10.2134/agronj2015.0408

Lee H.J., Kim H., and Kim O.W., 2016. Optimal harvest timing for maximizing grain yield and whole kernel ratio of shortgrain rice. Trans. ASABE, 59(2), 745-750. https://doi.org/10.13031/trans.59.11424

Li Y.N., and Ding W.M., 2010. Analysis on microstructure difference of ventral and dorsal side of rice grain (in Chinese). Scientia Agricultura Sinica, 43(16), 3 473-3 480.

Li Y.N., Li K., Ding W.M., and Chen K.J., 2014. Correlation of head rice yield to mechanical properties difference of rice kernels between dorsal side and ventral side. J. Food Eng., 123, 60-66. https://doi.org/10.1016/j.jfoodeng.2013.09.009

Lu R., Siebenmorgen T.J., Costello T.A., and Fryar Jr E.O., 1995. Effect of moisture content at harvest on economic return. Appl. Eng. Agric., 11(5), 685-690. https://doi.org/10.13031/2013.25792

Masahiko T., Shingo K., Miyuki T., and Takao T., 2007. Hardness distribution and endosperm structure on polishing characteristics of brewer's rice kernels. Plant Production Sci., 10(4), 481-487. https://doi.org/10.1626/pps.10.481

Qin G., and Siebenmorgen T.J., 2005. Harvest location and moisture content effects on rice kernel-to-kernel breaking force distributions. Appl. Eng. Agric., 21(6), $1011-1016$. https://doi.org/10.13031/2013.20016

Shao X.L., Wang N., Shi X.Z.H., Shen F., Song W., and Zhang Q., 2017. Analysis of moisture state and transverse relaxation characteristics of grains during the growth process of rice. Scientia Agricultura Sinica, 50(2), 240-249.

Siebenmorgen T.J., Bautista R.C., and Counce P.A., 2007. Optimal harvest moisture contents for maximizing milling quality of long and medium-grain rice cultivars. Appl. Eng. Agric.,23(4),517-527.https://doi.org/10.13031/2013.23476

Siebenmorgen T.J., Counce P.A., Lu R., and Kocher M.F., 1992. Correlation of head rice yield with individual kernel moisture content distribution at harvest. Trans. ASAE, 35(6), 1879-1884. https://doi.org/10.13031/2013.28810

Siebenmorgen T.J., Qin G., and Jia C., 2005. Influence of drying on rice fissure formation rates and mechanical strength distributions. Trans. ASAE, 48(5), 1835-1841. https://doi.org/10.13031/2013.19981

Som B., Pao S., Late Hourn S., Yim S., Sareth Ch., Makara O., Chao S., Nob L., Hel S., Yong R., Jaquie M., and Shu F., 2019a. Fissured grain and head rice yield of crops harvested manually or by combine at different ripening stages in Cambodia. Plant Production Sci., 22(1), 88-97. https://doi.org/10.1080/1343943X.2018.1538700 
Som B., Hourn S., Yim S., Ngon N., Loan M., Sareth Ch., Makara O., Jaquie M., and Shu F., 2019b. Head rice yield of crops harvested by combine and hand at different ripening times in cambodia. Exp. Agric., 55(1), 132-142. https://doi.org/10.1017/S0014479717000606

Thompson J.F. and Mutters R.G., 2006. Effect of weather and rice moisture at harvest on milling quality of California medium-grain rice. Trans. ASABE, 49(2), 435-440.

Wu X.B., Liu J.X., Li D.Q., and Liu C.M., 2016. Rice caryopsis development II: Dynamic changes in the endosperm. J. Integrative Plant Biol., 58(9), 786-798. https://doi.org/10.1111/jipb.12488

Xiong F., Wang Z., Cheng G., and Wang J., 2005. Caryopsis development and main quality characteristics in different indica rice varieties. Rice Sci., 12(4), 238-242.
Zhang Q., Yang W., Howard L., and Earp C.F., 2003. Tracing fissure information by scanning electron microscopy characterization of naturally fissured surfaces of rice kernels. Trans. ASAE, 46(6), 1 583-1 588.

https://doi.org/10.13031/2013.15619

Zhang Q., Yang W., and Sun Z., 2005. Mechanical properties of sound and fissured rice kernels and their implications for rice breakage. J. Food Eng., 68(1), 65-72. https://doi.org/10.1016/j.jfoodeng.2004.04.042

Zheng Y.K., Zeng D.E., Wei H.P., Xu Y., Gu Y.J., and Wang Z., 2017. Structure observation of rice endosperm tissues (in Chinese). China J. Rice Sci., 31(1), 91-98. 